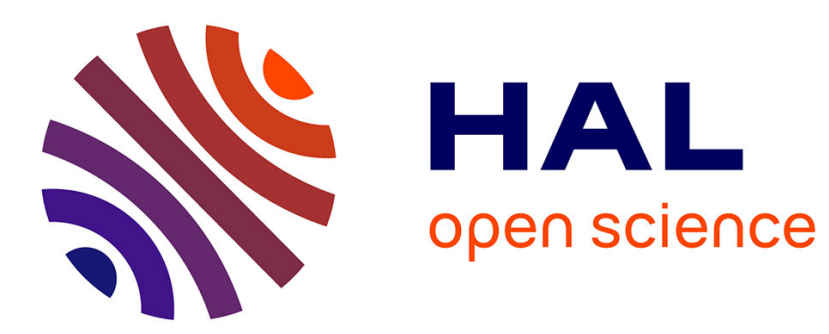

\title{
Vibration level induced by the friction of two rough surfaces weakly loaded
}

\author{
Modeste Assemien, Alain Le Bot
}

\section{To cite this version:}

Modeste Assemien, Alain Le Bot. Vibration level induced by the friction of two rough surfaces weakly loaded. Inter-noise 2021, Aug 2021, Washington (virtual), United States. 10.3397/IN-2021-1795 . hal-03343688

\section{HAL Id: hal-03343688 \\ https://hal.science/hal-03343688}

Submitted on 14 Sep 2021

HAL is a multi-disciplinary open access archive for the deposit and dissemination of scientific research documents, whether they are published or not. The documents may come from teaching and research institutions in France or abroad, or from public or private research centers.
L'archive ouverte pluridisciplinaire HAL, est destinée au dépôt et à la diffusion de documents scientifiques de niveau recherche, publiés ou non, émanant des établissements d'enseignement et de recherche français ou étrangers, des laboratoires publics ou privés. 


\title{
$\frac{1}{\text { inter-noise 2021 }}$ \\ 1-5 August | Washington, DC
}

\section{Vibration level induced by the friction of two rough surfaces weakly loaded}

\author{
Modeste Assemien ${ }^{1}$ \\ Ecole Centrale de Lyon, LTDS \\ 36 Avenue Guy de Collongue, 69134 Ecully, France
}

Alain Le Bot ${ }^{2}$

Ecole Centrale de Lyon, CNRS LTDS

36 Avenue Guy de Collongue, 69134 Ecully, France

\begin{abstract}
This paper presents an experiment to measure the vibration level generated when a light solid slides over a dry and rough surface. The experimental set-up is based on linear constant motion with speed range from 1 to $1000 \mathrm{~mm} / \mathrm{sec}$. The aim is to study the evolution of the vibration level as a function of the sliding speed and the friction area. Measurements show that the vibration level is a logarithmic increasing function of the sliding speed with a transient velocity. It is also observed that two regimes exist for the evolution of vibration level versus apparent contact area. On the one hand the vibration level is proportional to the friction area, but on the other hand this level is constant.
\end{abstract}

\section{INTRODUCTION}

The noise produced by the friction of two rough and dry surfaces weakly loaded, also called roughness noise, is a wideband noise with generally a small sound level, it is characterized by light contact pressure and percussion at the top of antagonist asperities. The micro-impact behaves like small hammer strokes, excite the structure which produces vibration responsible of emitted noise [1]. The studies of the phenomenology of roughness noise have previously shown the dependence between sound pressure level or vibrational level, surface roughness [2,3], sliding speed [4] and contact area [7].

This paper reports an experimental study on vibrational level versus sliding speed and contact area for flat-flat dry contact. The aim is to establish, on one hand, the scaling laws between vibrational level $L v$ and sliding speed and the other hand between $L v$ and contact area.

The paper is organized as follows. In section 2, we present the principle, the experimental device and the procedure of the experiment. Results and discussion are presented in Section 3 while conclusions are given in Section 4.

\footnotetext{
${ }^{1}$ nguetta.assemien@ec-lyon.fr

2alain.le-bot@ec-lyon.fr
} 


\section{MEASUREMENT OF VIBRATION LEVEL}

\subsection{Principle and experimental device}

The experiment consists in rubbing the rough face of light metallic block, called slider, on the rough surface of a suspended thin plate with a very low internal dissipation (Figure 1). The metallic block is sliding at constant speed and the vibrational velocity is recorded by a laser vibrometer.

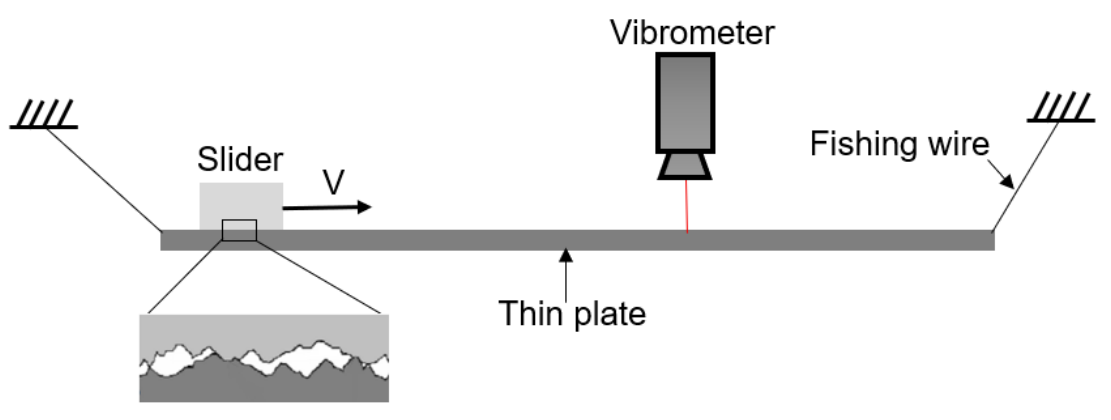

Figure 1: Principle of the experiment.

The different components of the experimental setup is shown in Figure 2. The sliding motion of the slider is insured by a small brushless motor (type AKM31C class F). The thin plate, also called resonator, is attached to an aluminum frame structure using fishing wire. It's a rectangular plate made of stainless steel with size $600 \mathrm{~mm}$ long, $400 \mathrm{~mm}$ wide and $4 \mathrm{~mm}$ thick. The size of the rough zone of the plate is $460 \times 20 \mathrm{~mm}$. The slider is made of the same material as the resonator and of size 20 $\times 20 \times 10 \mathrm{~mm}$

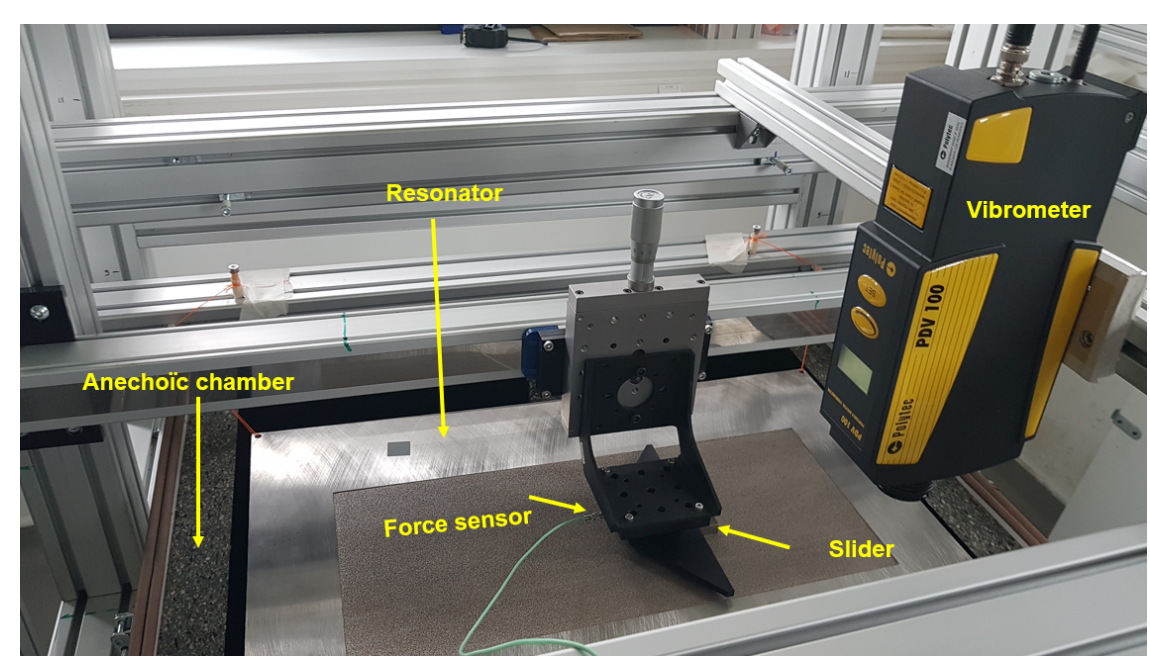

Figure 2: Experimental device.

Table 2 outlines the mechanical characteristics of the resonator and the slider. The rough surfaces have been prepared by electrical discharge machining (EDM). The surface of the resonator and the slider are Gaussian (Table 1). 
Table 1: Characteristics of the slider and resonator

\begin{tabular}{lcc}
\hline Material properties & Slider & Resonator \\
\hline Size $(\mathrm{mm})$ & $20 \times 20 \times 10$ & $600 \times 400 \times 4$ \\
\hline Young's modulus, $E(\mathrm{GPa})$ & 210 & 210 \\
\hline Poisson's ratio, $v$ & 0.3 & 0.3 \\
\hline Density, $\rho\left(\mathrm{kg} / \mathrm{m}^{3}\right)$ & 7800 & 7800 \\
\hline Mass, $(\mathrm{g})$ & 31.2 & 7488 \\
\hline
\end{tabular}

Table 2: Topography parameters obtained by profilometer

\begin{tabular}{lcc}
\hline Parameters & Resonator & slider \\
\hline $\mathrm{Rq}(\mu \mathrm{m})$ & $17,10 \pm 0.5$ & $16,62 \pm 0.38$ \\
\hline $\mathrm{Rsk}(\mu \mathrm{m})$ & $0,37 \pm 0.04$ & $0,36 \pm 0.11$ \\
\hline $\mathrm{Rku}(\mu \mathrm{m})$ & $2,70 \pm 0.25$ & $2,96 \pm 0.18$ \\
\hline
\end{tabular}

\subsection{Experimental procedure}

The experiment is run in ambient atmosphere ( $\mathrm{RH}=72$ to $76 \%$ and $\mathrm{T}=21$ to $23{ }^{\circ} \mathrm{C}$ ). The cleaning of the surfaces is one of the most important steps in order to obtain an acceptable reproductivity of the experiment. Before test, the rough area of the resonator and the sliders are cleaned. Each cleaning process is first done with heptane to remove all greases on the surfaces and followed respectively by acetone to ensure no residual traces of chemical remains on the surface. The surface is finally dried under a flux of nitrogen. After the cleaning procedure, the plate is attached to the aluminum frame structure using fishing lines. The slider is then carefully placed on the resonator with its rough surface in contact with that of the resonator. It is noted that the plate and the sliders are to be handled with gloves to avoid contamination of rough surfaces. Move the slider at constant speed in the range 1 to $1000 \mathrm{~mm} / \mathrm{s}$ and record the vibrational velocity by the vibrometer. For each sliding speed, repeat the test five times.

\section{RESULTS AND DISCUSSION}

\subsection{Vibration level versus sliding speed}

The measurements are carried out in a bandwidth ranging from $10 \mathrm{~Hz}$ to $10 \mathrm{kHz}$ at sampling frequency $51200 \mathrm{~Hz}$. The vibration level is calculated with the following relationship:

$$
L_{v}(d B)=20 \log _{10} \frac{V_{R M S}}{V_{0}}
$$

where $V_{R M S}=\sqrt{\frac{1}{T_{2}-T_{1}} \int_{T_{1}}^{T_{2}} v^{2}(t) d t}$ is the RMS velocity of the plate, $V_{0}=10^{-6} \mathrm{~mm} / \mathrm{s}, v$ denote the vibrational velocity.

Figure 3 presents the evolution of the vibrational level $L_{v}(d B)$ as a function of the logarithm of sliding speed $V . L_{v}(d B)$ is an increasing function of the sliding speed according to the following 
scaling law:

$$
L_{v}(d B) \propto 20 \log _{10} V^{n}
$$

where $n=0.75$ for $V<120 \mathrm{~mm} / \mathrm{s}$ and $n_{2}=0.1$ for $V>120 \mathrm{~mm} / \mathrm{s}$.

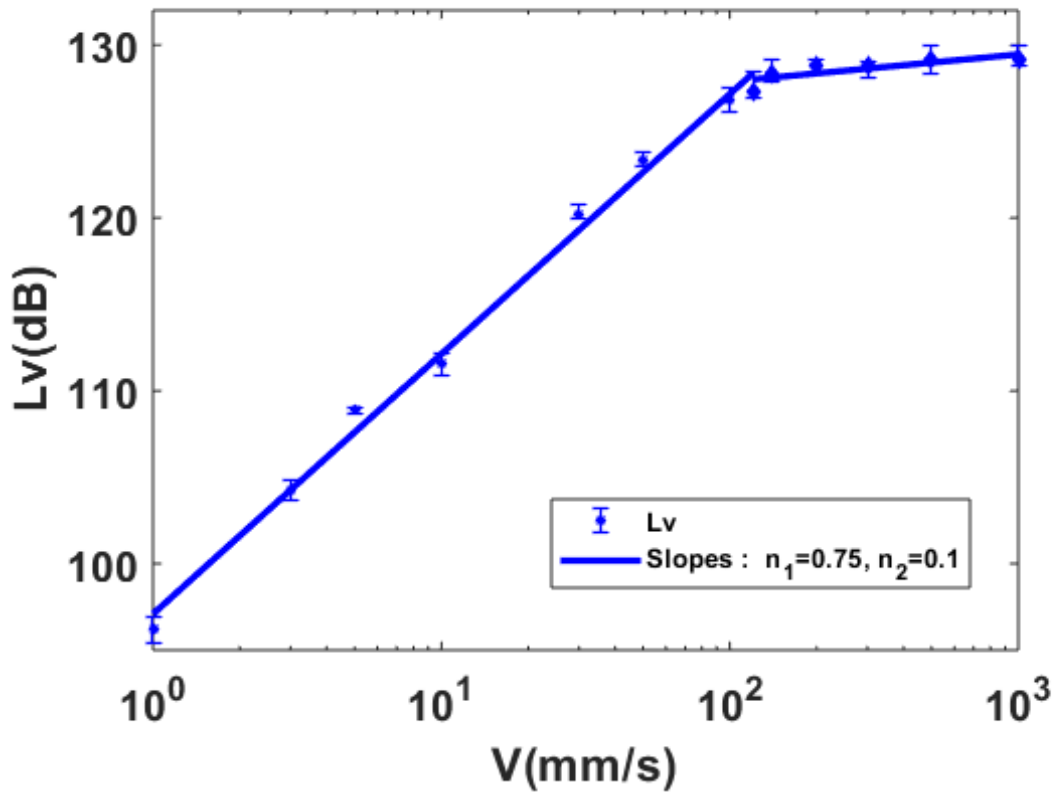

Figure 3: Evolution of vibration level Lv versus sliding speed V.

The evolution vibrational level versus sliding speed shows two regimes with transient speed $\mathrm{V}=120$ $\mathrm{mm} / \mathrm{s}$. The creeping regime appears up to $120 \mathrm{~mm} / \mathrm{s}$, in this regime the contact rate is high. From $120 \mathrm{~mm} / \mathrm{s}$ the contact is rare and the slider is in free flight. The slopes of the linear increasing function of the vibrational level versus the logarithm of the sliding speed of the two regimes are $n_{1}=0.75$ and $n_{2}=0.1$. In literature, the exponent of the scaling law (Equation 2) for flat-flat rough contact are respectively : $0.7 \leq n \leq 0.96[4,5], 0.7 \leq n \leq 0.85$ [8], $0.71 \leq n \leq 0.79[11,12]$ and $0.76 \leq n \leq 0.77$ [13]. The results of our study are in agreement with previous investigation but also highlight a transient speed with another exponent.

\subsection{Vibration level versus contact area}

The vibrational RMS velocity is measured when rubbing from 1 to 24 sliders $\left(S=4-96 \mathrm{~cm}^{2}\right)$ for a constant sliding speed V=100 mm/s. Figure 4 shows the evolution of the vibrational level versus contact area. The vibrational level increase from 127,7 to $129,76 \mathrm{~dB}$ for 1 up to 12 sliders and remains constant from 12 sliders.

The effect of contact area on vibration level shows the existence of two regimes. In the first regime, the vibrational level $L v$ is proportional to the contact area while in the second one, it is constant. Concerning the relationship of $L v(d B)$ with contact area, Le Bot et al. [7,9] found that the dissipation in rough contact depend of the energy within the contact and also the vibration of the solids in contact. The internal damping of the solid dominates when the vibrational level increases with the number of sliders and when the vibrational remains constant, the contact damping dominates $[9,10]$. The present study is in agreement with the previous observations. The vibrational level induced by the rubbing of two rough surfaces is a very complex phenomenon. 


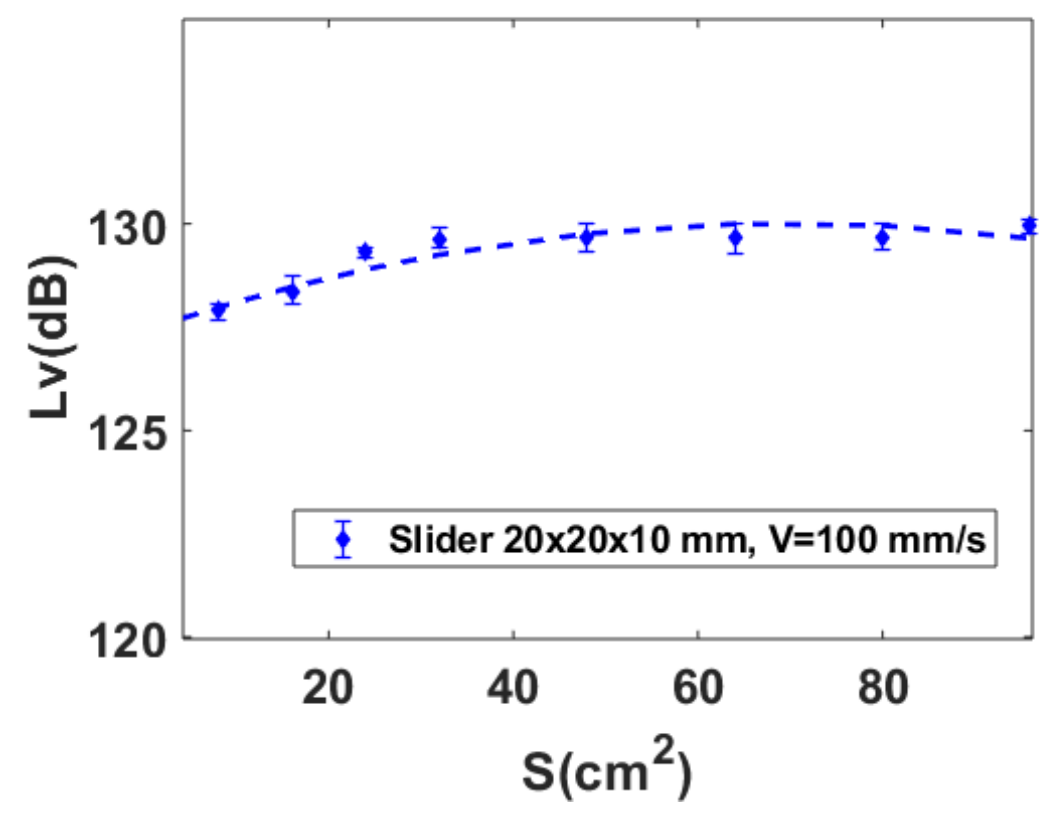

Figure 4: Vibrational level $L v(d B)$ versus contact area $S\left(\mathrm{~cm}^{2}\right)$ for a slider $20 \times 20 \times 10 \mathrm{~mm}$ at constant $V=100 \mathrm{~mm}$.

\section{CONCLUSIONS}

This paper focus on study of vibrational level versus sliding speed and contact area, it has been shown experimentally that the vibrational level is a linear increasing function of the logarithm of sliding speed with transient speed $V=120 \mathrm{~mm} / \mathrm{s}$ and two slopes $n_{1}=0.75$ and $n_{2}=0.1$. In term of contact area, two regimes exist for the dependence of vibrational level $L v$ with contact area $S$. In the first regime, $L v$ is proportional to $S$ while in the second one, $L v$ is constant.

\section{ACKNOWLEDGEMENTS}

The authors gratefully acknowledge the French National Centre for Scientific Research.

\section{REFERENCES}

[1] A. Le Bot. Noise of sliding rough contact. Journal of Physics : Conferences Series, 797:012006, 2017.

[2] M. Nakai and M. Yokoi. A Fundamental Study on Friction Noise. Bulletin of the JSME, 25(203):827-833, 1982.

[3] M. O. Othman, A. H. Elkholy, and A. A. Seireg. Experimental investigation of friction noise and surface-roughness characteristics. Experimental Mechanics, 25(14):328-331, 1990.

[4] H. Ben Abdelounis, A. Le Bot, J. Perret-Liaudet, and H. Zahouani. An experimental study on roughness noise of dry rough flat surfaces. Wear, 268:335-345, 2010.

[5] H. Ben Abdelounis, H. Zahouani, A. Le Bot, J. Perret-Liaudet, and M. B. Tkaya. Numerical simulation of friction noise. Wear, 271, 621-624, 2010.

[6] H. Ben Abdelounis. Dynamique et vibroacoustique du contact rugueux : expérimentation et modélisation. Ph.D. thesis, Ecole Centrale de Lyon, France, 2010.

[7] A. Le Bot and E. Bou-Chakra. Measurement of Friction Noise Versus Contact Area of Rough Surfaces Weakly Loaded. Tribology Letters, 37:273-281, 2010. 
[8] B. L. Stoimenov, S. Maruyama, K. Adachi, and K. Kato. The roughness effect on the frequency of frictional sound. Tribology International, 40(4):659-664, 2007.

[9] A. Le Bot, E. Bou-Chakra, and G. Michon. Dissipation of vibration in rough contact. Tribology Letters, 41:47-53, 2011.

[10] A. Le Bot. Foundation of Statistical Energy Analysis in Vibroacoustics. Oxford University Press, Oxford, United Kingdom, 2015.

[11] V. H. Dang. Dynamique des interfaces multicontact. Ph.D. thesis, Ecole Centrale de Lyon, France, (2013).

[12] V. H. Dang, J. Perret-Liaudet, J. Scheibert, and A. Le Bot. Direct numerical simulation of the dynamics of sliding rough surfaces. Computation Mechanics, 52, 1169-1183, 2013.

[13] M. Assemien and A. Le Bot. INFLUENCE OF SLIDING SPEED ON ROUGHNESS NOISE. Proceedings of 26th International Congress on sound and Vibration, Montreal, Canada, July 2019. 